Please do not remove this page

RMIT

UNIVERSITY

\title{
Progressive damage in single lap countersunk composite joints
}

Chishti, Maajid; Wang, Chun; Thomson, Rodney; Orifici, Adrian

https://researchrepository.rmit.edu.au/esploro/outputs/9921858443901341/filesAndLinks?institution=61RMIT_INST\&index=null

Chishti, M., Wang, C., Thomson, R., \& Orifici, A. (2010). Progressive damage in single lap countersunk composite joints. IOP Conference Series: Materials Science and Engineering, 10, 1-6.

https://doi.org/10.1088/1757-899X/10/1/012064

Document Version: Accepted Manuscript

Published Version: https://doi.org/10.1088/1757-899X/10/1/012064

Repository homepage: https://researchrepository.rmit.edu.au

(c) 2010 Published under licence by IOP Publishing Ltd

Downloaded On 2023/04/26 22:23:37 +1000 
Thank you for downloading this document from the RMIT Research Repository.

The RMIT Research Repository is an open access database showcasing the research outputs of RMIT University researchers.

RMIT Research Repository: http://researchbank.rmit.edu.au/

\section{Citation:}

Chishti, M, Wang, C, Thompson, R and Orifici, A 2010, 'Progressive damage in single lap countersunk composite joints', IOP Conference Series: Materials Science and Engineering, vol. 10, pp. 1-6.

See this record in the RMIT Research Repository at:

http://researchbank.rmit.edu.au/view/rmit:12865

Version: Accepted Manuscript

Copyright Statement: (c) 2010 Published under licence by IOP Publishing Ltd

Link to Published Version:

http://dx.doi.org/10.1088/1757-899X/10/1/012064 


\title{
Progressive Damage in Single Lap Countersunk Composite Joints
}

\author{
Maajid Chishti ${ }^{1}$, Chun Hui Wang ${ }^{1 *}$, Rodney S. Thomson ${ }^{2}$, Adrian Orifici ${ }^{1}$ \\ ${ }^{1}$ The Sir Lawrence Wackett Aerospace Centre, School of Aerospace, Mechanical and \\ Manufacturing Engineering, RMIT University, GPO Box 2476, Melbourne VIC 3001, \\ Australia \\ ${ }^{2}$ Cooperative Research Centre for Advanced Composite Structures Limited, 506 \\ Lorimer street, Fishermans Bend VIC 3207, Australia \\ *chun.wang@rmit.edu.au
}

\begin{abstract}
This paper presents an experimental and computational investigation of the influences of countersink and bolt torque on the progressive failure of single-lap composite joint. Using the Abaqus ${ }^{\circledR}$ software, delamination damage and ply fracture are modelled using cohesive element approach and continuum damage mechanics method, respectively. The model is first validated against a filled-hole tension test to calibrate the composite damage model. Comparison with the experimental results indicates that the computational model is capable of accurately predicting the joint strength and the damage progression process.
\end{abstract}

\section{Introduction}

In aerospace structures, composite components are often fastened to other structural members by bolted joints, with or without the use of adhesive bonding. Despite the many advantages of adhesive bonding, bolted joints are still used because of easy of assembly/disassembly and airworthiness certification. The lack of non-destructive inspection technique for detecting weak bond means that certifying adhesively bonded structures remains unresolved. However, the introduction of bolts leads to complicated three dimensional (3D) stress fields near the bolt hole [1]. In the case of composite skin structures, the use of countersunk fasteners further elevates the stress concentration above that pertinent to non-countersunk, straight hole. The higher stresses due to the countersunk fastener will further reduce the joining efficiency of laminated composites. To take full advantage of fiber reinforced composite materials in structural elements, appropriate methods for stress and failure analysis are required to enable efficient design and computational optimization of joint design. Research in the field of 3D bolted joint analysis have mostly concentrated on straight shank bolt [2], with limited work on countersunk bolted joints [3][4].

Uncertainties regarding the strength and failure of critical composite joints may lead to conservative, inefficient design and structural weight penalty cancelling the major advantage of composite materials. However, non-conservative design approaches may lead to catastrophic inservice failure of the structure. It is important to fully understand the strength and failure behaviour of countersunk composite bolted joints. The present work aims to investigate the influences of countersink and bolt torque on the strength of single-lap joints. Experiments are conducted to 
determine the responses of single lap joints fastened using protruding-head and countersunk bolts. The experimental results are employed to validate the computational model.

\section{Experimental testing}

The testing program consists of two experimental procedures. A set of filled-hole tests and single-lap joint tests are conducted on carbon/epoxy composite. Test coupons are made of plain weave pre-preg material in accordance with the manufacturer's recommended curing process. A quasi-isotropic lay-up sequence $\left[(0 / 45)_{4}\right]_{\mathrm{S}}$ is used for both the filled-hole and single-lap testing. The tests are conducted using MTS $^{\circledR}$ testing machine at a displacement controlled loading rate of $0.5 \mathrm{~mm} / \mathrm{min}$. The specimens for both filled hole and single lap tests are designed according to the ASTM [5] standard.

\subsection{Bearing strength test}

The dimensions of bearing-test specimen can be seen from Figure 1. A strain gage (SG) is located at about $7 \mathrm{~mm}$ from the hole edge as shown in Figure 1. To promote bearing failure, both the edge distance e/d and width ratio $\mathrm{w} / \mathrm{d}$ are set to 5 . Here the parameters $e=$ edge distance, $w=$ specimen width and $d=$ hole diameter. The location of the strain gage and extensometer tab on the specimen is also depicted in Figure 1. The attached extensometer and test fixture is shown in Figure 2. The extensometer is secured to the test fixture, which is made of high strength steel at twice the thickness of the composite laminate. A structural steel bolt is used as the pin. The test fixture does not provide any lateral support to the specimen. The results obtained from this test are used for finite element model calibration and benchmarking. The strength and stiffness properties are shown in Table 1.

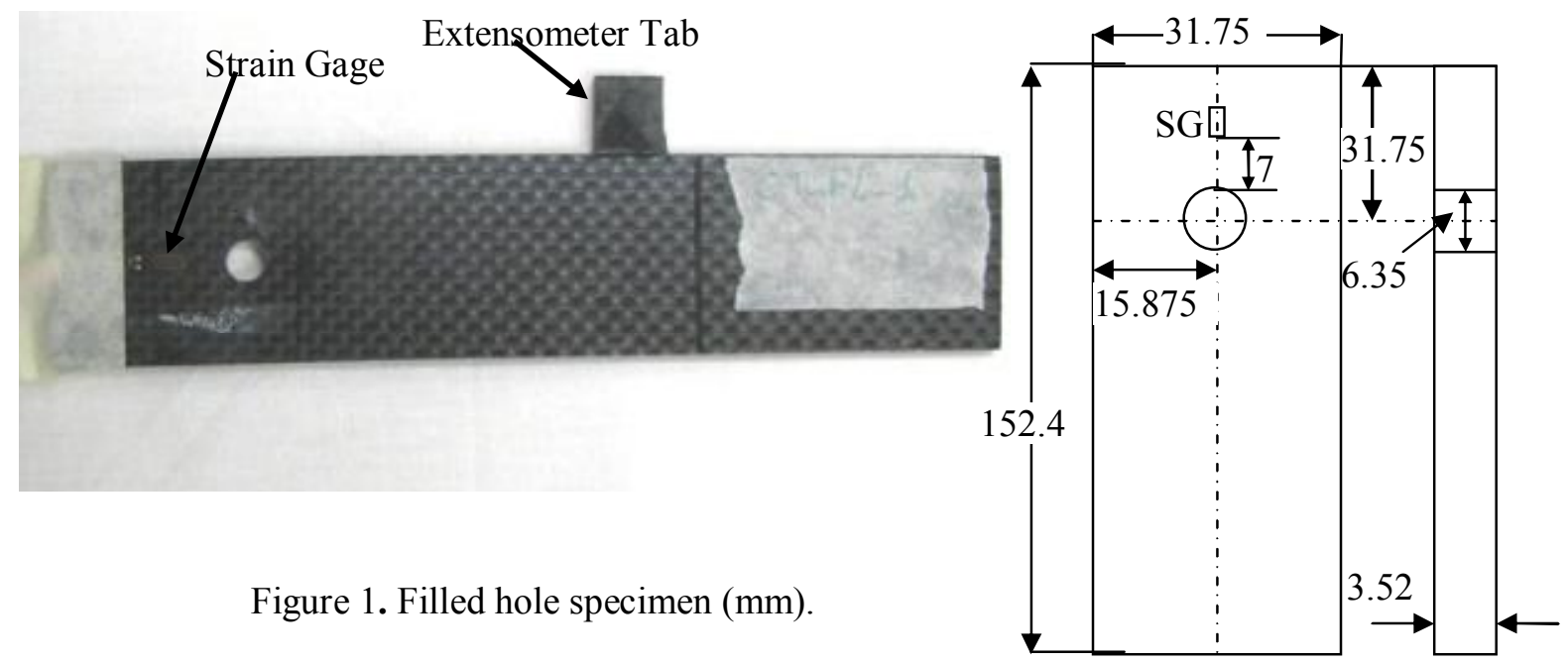

Table 1 Material properties.

\begin{tabular}{|cccccc|}
\hline \multicolumn{7}{c|}{ Stiffness Properties, GPa } \\
\hline $\mathrm{E}_{11}$ & $\mathrm{E}_{22}$ & $\mathrm{G}_{12}$ & $\mathrm{G}_{13}$ & $\mathrm{G}_{23}$ & $v_{11}$ \\
\hline 85 & 5.2 & 2.4 & 2.4 & 1.9 & 0.3 \\
\hline & \multicolumn{7}{c}{ Strength Properties, MPa } & & \\
\hline $\mathrm{S}_{11 \mathrm{~T}}$ & $\mathrm{~S}_{11 \mathrm{C}}$ & $\mathrm{S}_{22 \mathrm{~T}}$ & $\mathrm{~S}_{22 \mathrm{C}}$ & $\mathrm{S}$ & $\mathrm{S}_{\mathrm{T}}$ \\
\hline 1009 & 865 & 81 & 188 & 69 & 62 \\
\hline
\end{tabular}

\subsection{Single-lap joint test}

The countersunk single lap joint tests are conducted with the same test machine and setting as the bearing-strength test. The tests are conducted to understand the effects of bolt torque (BT) on the performance of countersunk single lap joint. The geometry of the single lap joint is provided in Figure 
3 , together with strain gage locations. Table 2 provides the dimensions and torques used for the singlelap joint tests. The strain gages are placed so that the gages located on the top laminate aligned with the gages located on the bottom laminate. Due to this the strain gage location of the bottom laminate (SLB) is $7 \mathrm{~mm}$ where as the strain gage location of the top laminate (SLT) is $5 \mathrm{~mm}$. Due to inaccuracies in the measurement of end displacement from the testing machine extensometer is employed to measure specimen displacement versus load. The extensometer is attached to the specimen using tabs on the side of the specimen. The tabs are vertically aligned at about $12 \mathrm{~mm}$ apart horizontally. An attachment for the extensometer is designed and calibrated. For all the tests the grip length is kept constant at $50 \mathrm{~mm}$. The experimental setup for single lap test together with strain gauge (SG) locations and extensometer attachment can be seen from Figure 4. Top laminate's SG1 and SG2 have bottom laminate's SG4 and SG3 as the corresponding strain gages.
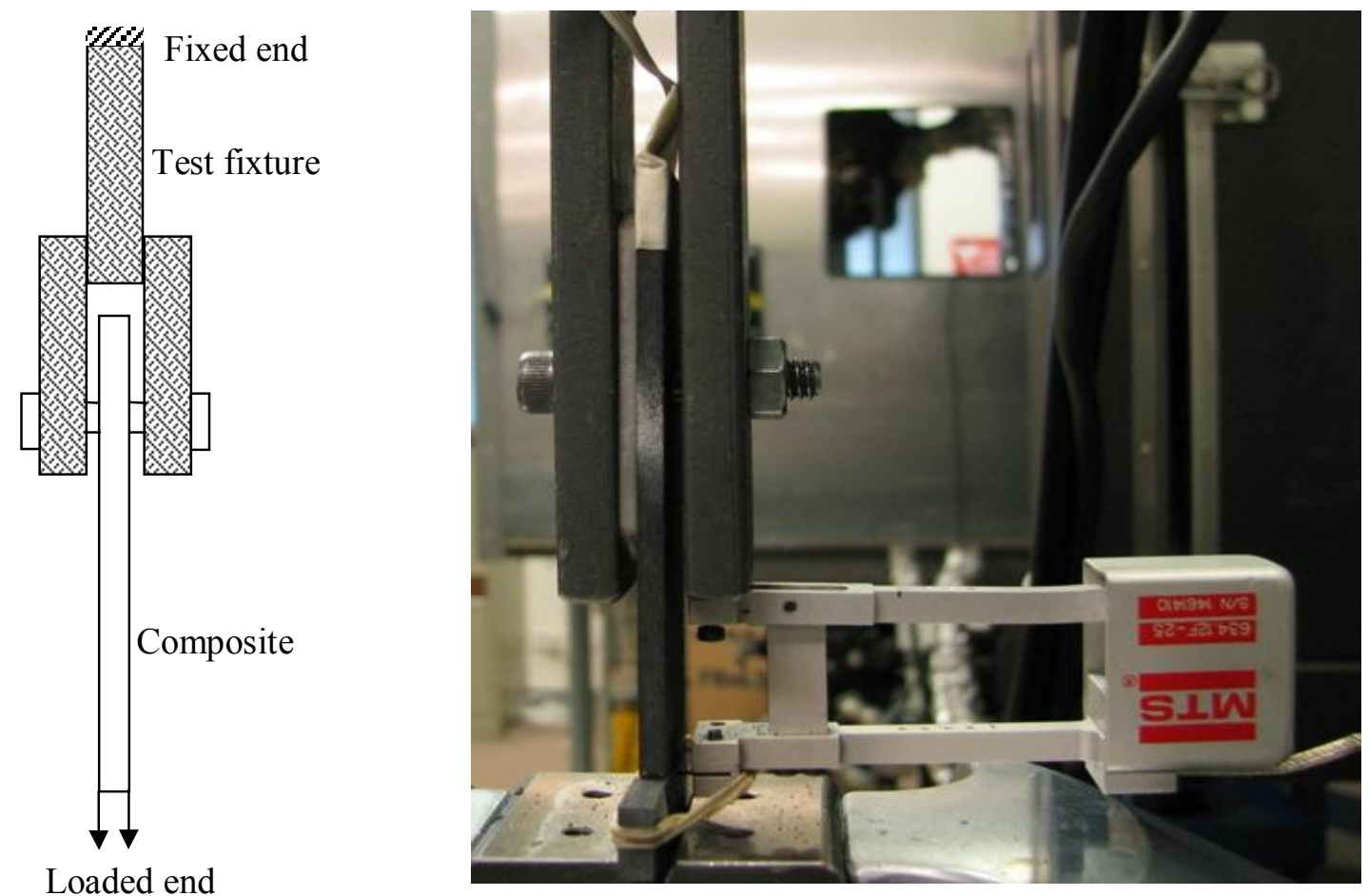

Figure 2. Test fixture and extensometer attachment.

Hi-Lok ${ }^{\circledR}$ [6] HL13 and HL86 fastener system was used for bolt and nut respectively. The selected system represents fasteners commonly used in aerospace industry. The torque was applied using a calibrated torque wrench. For the selected nut the manufacturer's recommended maximum torque value is approximately $5.65 \mathrm{Nm}$, however, the nut was not tightened to the maximum value because of an inability to achieve the value consistently.

Table 2 Single lap dimensions $(\mathrm{mm})$ and Torque $(\mathrm{Nm})$.

\begin{tabular}{|c|c|c|c|c|c|c|c|c|c|c|c|}
\hline Test & $\mathrm{L}$ & $\mathrm{t}$ & $\mathrm{W}$ & $\mathrm{e}$ & D & A & OL & Plies & HT & SLT & SLB \\
\hline BT & 152.4 & 3.52 & 31.75 & 31.75 & 4.76 & 9.5631 & 63.5 & 16 & 0.56 & 5 & 7 \\
\hline Tor & & \multicolumn{2}{|c|}{ BT1 } & \multicolumn{4}{|c|}{ BT2 } & \multicolumn{4}{|c|}{ BT3 } \\
\hline Val & & \multicolumn{2}{|c|}{0} & & \multicolumn{2}{|c|}{2.103} & & \multicolumn{4}{|c|}{4.206} \\
\hline
\end{tabular}




\section{Finite Element Modelling}

The FE model is created in ABAQUS ${ }^{\circledR}[7]$ software. Each layer of plain weave carbon/expoxy composite is divided into two unidirectional plies to give the same stiffness and strength as the woven ply. The composite is modelled using 3D continuum shell elements, which enable the application of the continuum damage model available in ABAQUS 6.9. Hashin [8] failure criteria are used for composite failure initiation, while the crack-band based continuum damage mechanics approach is employed to tract ply fracture. Hashin criteria account for four different failure modes of composites: fibre tension, fibre compression, matrix tension, and matrix compression.

\section{Bottom laminate}

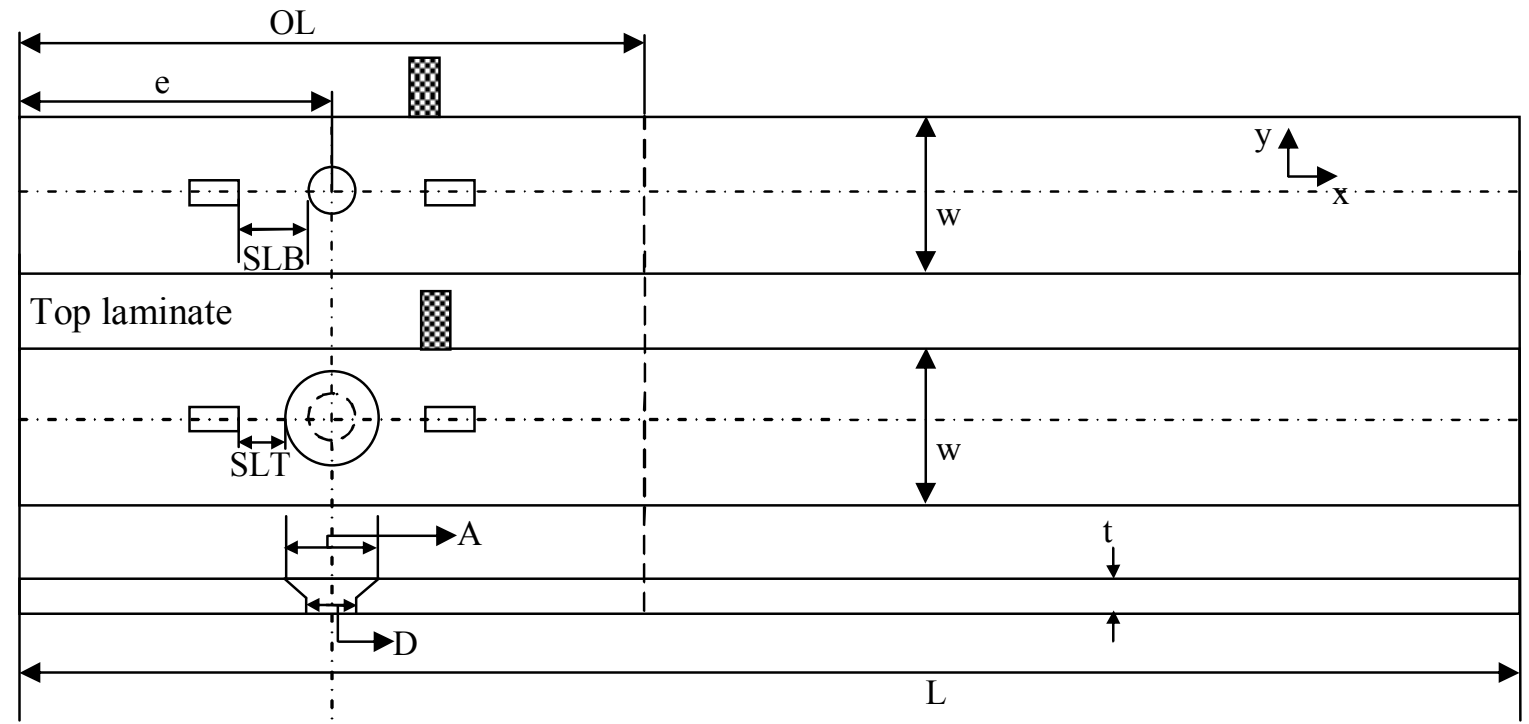

Figure 3. Single lap joint geometry.
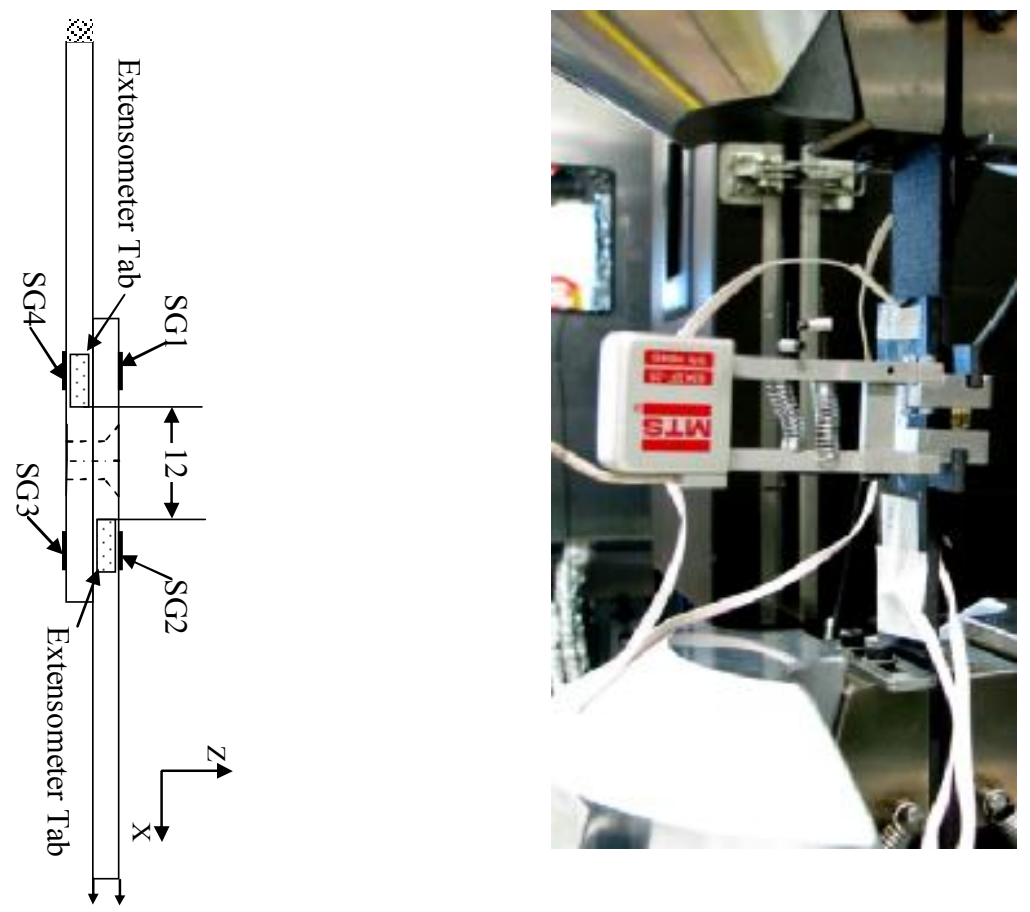

Figure 4. Location of strain gages and extensometer tab, (mm). 
Hashin criteria provide a good approximation of fibre failure initiation; however, according to Echaabi et al [9] and Paris [10], Hashin criteria are not very accurate for matrix failure. Since ABAQUS currently does not support any other failure criteria for composite damage modelling, we adopt Paris's recommendations [10] of not identifying $S_{T}$ with $S$. Here $\mathrm{S}_{\mathrm{T}}$ denotes the transverse shear strength (allowable value of $\tau_{23}$ ), where $S$ denotes the interlaminar shear strength (allowable value of $\left.\tau_{12}\right)$. The material properties listed in Table 1 are calibrated by comparing experimental results with predictions of micromechanics models.

A mesh sensitivity study is first conducted using the bearing-strength test. Figure 5 shows the three different meshes used in the mesh sensitivity study. Mesh 1 has 32 elements around the hole, while meshes 2 and 3 have respectively 56 and 80 elements. The variation of results between mesh 2 and 3 is approximately $1.7 \%$, confirming that the crack-band approach is capable to overcoming the mesh size sensitivity. Herein mesh 2 will be used in subsequent analyses. The complete setup of the bearingstrength test FE model is shown in Figure 6 . The use of a rigid bolt and not modelling the test fixture provide better computational efficiency with minimal effect on the accuracy of the results. The loaded region of the composite is restricted in the $\mathrm{y}$ and $\mathrm{z}$ directions as the machine grip is only displacing in the $\mathrm{x}$ direction. The results of the model are compared with experiments and are provided in the next section. Once the approach for modelling has been established, the single lap joints are modelled using the same approach to validate the model against experimental results. The single lap model setup can be seen from Figure 7. The single lap joint is modelled in four different parts, viz. top laminate (laminate with countersunk hole), bottom laminate, countersunk bolt and nut.

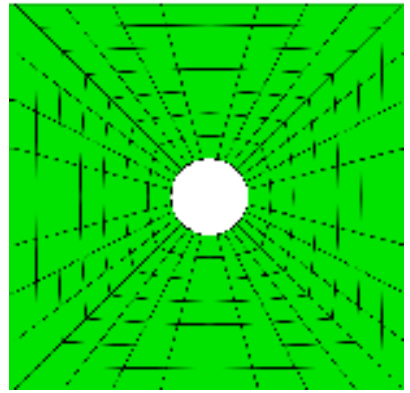

Mesh1

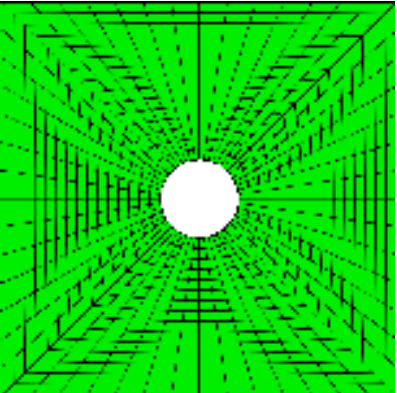

Mesh 2

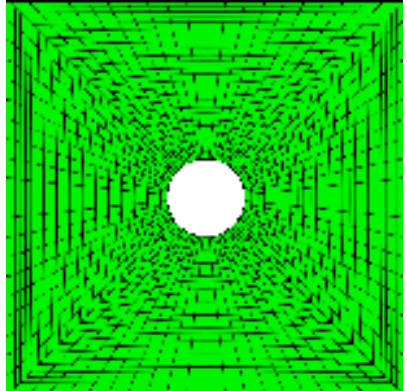

Mesh 3

Figure 5. Mesh density variation.

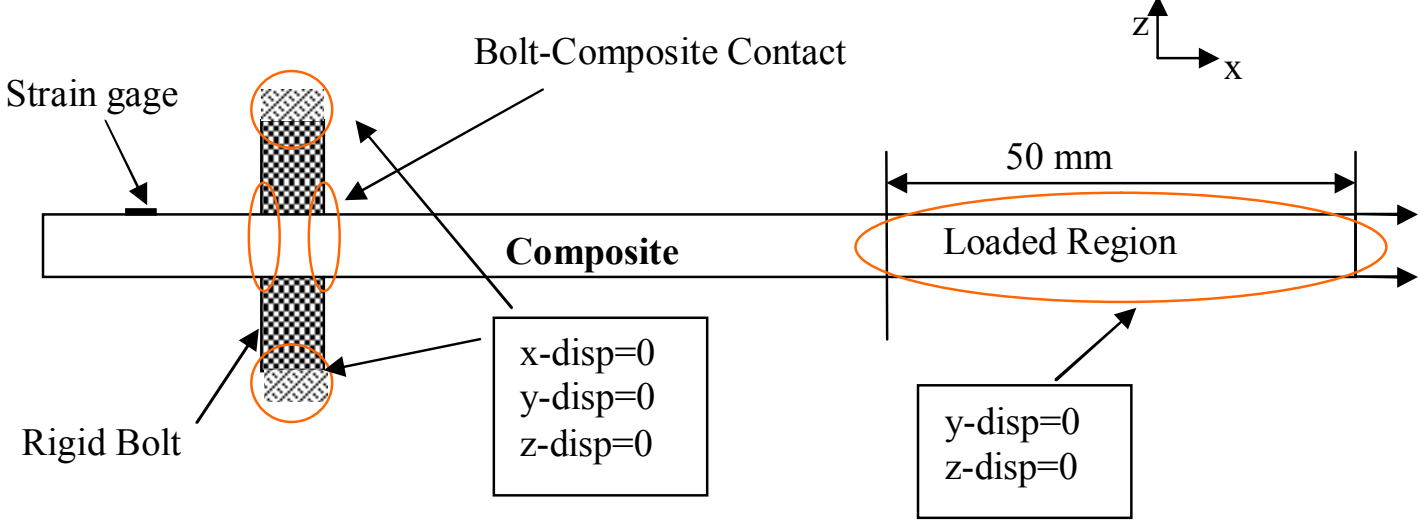

Figure 6. FE setup of filled hole model. 

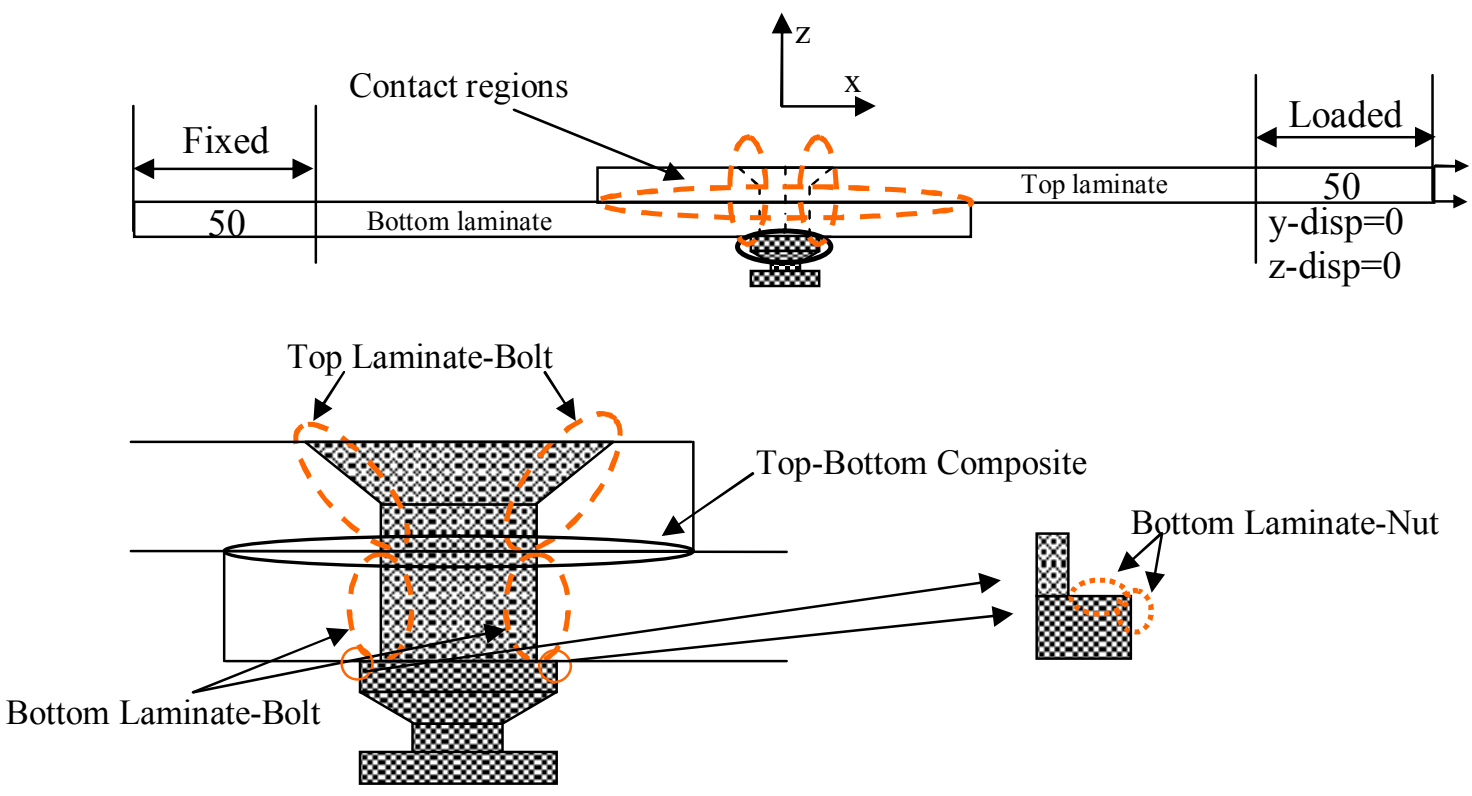

Figure 7. FE setup of single lap model (mm).

The bolt torque was applied by displacing the bolt in the vertical direction. It can be seen from Figure 7 that the model has a complicated contact region. Due to the bolt and nut bending it is important to apply the contact correctly and account for change in contact conditions later in the analysis. This leads to the inclusion of the side of the nut to be defined in the contact region as shown in Figure 7. The nut and bolt are modelled as rigid structures as no significant damage to the nut and bolt is noticed during experiments. This significantly improves the computational efficiency without affecting the results. The bottom laminate is fixed during testing and the load is applied on the top laminate. A displacement boundary condition is used to apply the load to the model.

During the initial simulation friction has not been applied to the model. The effects of friction become significant for highly-torqued bolts. Significant variation in the value of coefficient of friction has been reported in the literature [11] and [12]. The coefficient of friction was varied between 0.2 and 0.4. The value of 0.2 was used in the work because of being widely accepted and providing good comparison. The coefficient of friction was only used in single lap joint simulations. The results of experiments and simulations are provided in the next section.

\section{Results}

The experimental results are compared with computational simulations to validate the developed methodology. The calculated load-displacement behavior, failure load, initial stiffness and damage progression are compared to the experimental results. The following section provides the results of the comparative investigation on the bearing-strength tests and the single-lap joint tests.

\subsection{Bearing-strength test}

Composite bearing failure is the consequence of compressive failure of the laminate, in the form progressive accumulation of fibre kinking, fibre micro buckling, matrix crushing, etc [12]. Due to severe material and geometric nonlinearity associated with bearing, it is very difficult to replicate the complete bearing failure process in an FE model as significant element distortion can lead to early termination of the simulation. The current model is, nonetheless, able to capture a significant portion of the bearing failure process. A comparison of the final failure at the hole-edge is provided in Figure 8. The through thickness failure along longitudinal axis is shown in Figure 9. It can be seen that all the plies through the thickness are damaged. The top few plies in the experimental results are totally damaged due to accumulation of the bearing failure. This phenomenon is predicted satisfactorily by the computational model. 


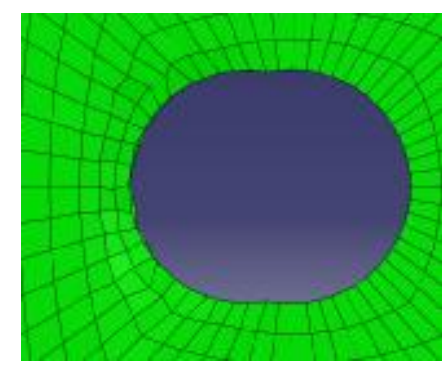

Finite Element

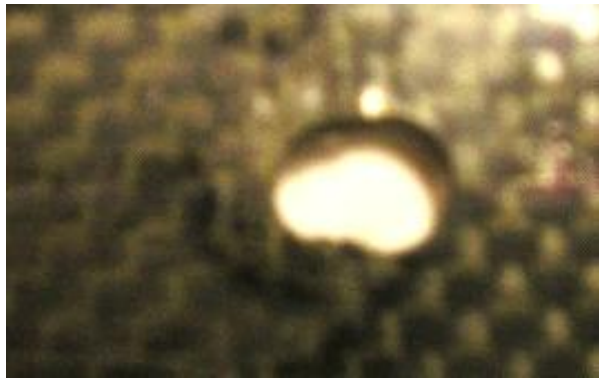

Experiment

Figure 8. Bearing failure.

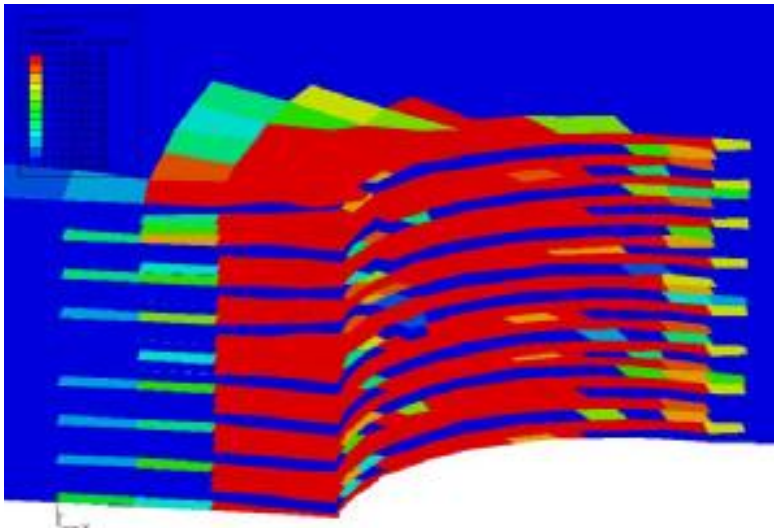

a)

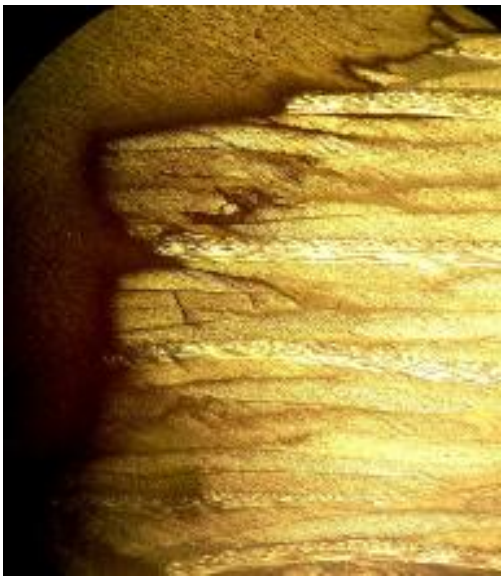

b)

Figure 9. Through thickness damage in $0^{\circ}$ direction.

The experimental and simulation load-displacement curves are shown in Figure 10. The initial elastic deformation predicted by the computer model agrees well with the experimental results. However, the peak strength at which non-linearity occurs differs by approximately $14 \%$. The post-elastic regime compares very well. Both experimental and computational results show increased stiffness after initial bearing failure. This can be attributed to the compaction of the damaged material which expands to give extra load carrying capacity before reaching the maximum value when the expansion of damaged material reaches a steady-state. The difference between the maximum experimental and predicted strength is approximately $1.7 \%$. It can be seen that overall failure mode, initial stiffness, and ultimate failure load are well predicted by the computational simulation. The progression of failure in the $0^{\circ}$ direction is shown in Figure 11. Part " $a$ " represents fibre failure and " $b$ " represents matrix failure. A large failed region can be seen at ultimate failure load significantly reducing further load carrying capacity of the structure.

\subsection{Single-lap joint using countersunk bolt}

As previously mentioned three different bolt torque are investigated. The effect of changing bolt torque on final failure load, failure displacement and overall load-displacement behaviour can be seen in Figure 12. The markers in Figure 12 show the location of maximum failure load and corresponding displacement. The experimental results clearly show that for the range of bolt torques tested there is no significant change in the characteristics of the single lap joint. The maximum failure load changes from $10.5 \mathrm{kN}$ for zero torque to $10.8 \mathrm{kN}$ for $2.103 \mathrm{Nm}$ torque and to $11.2 \mathrm{kN}$ for $4.206 \mathrm{Nm}$ torque. This shows that there is an increase of approximately $3.4 \%$ and $7.2 \%$ for $2.103 \mathrm{Nm}$ and $4.206 \mathrm{Nm}$ torque respectively. 
As expected there is a reduction in failure displacement. This occurrence is due to the increased effect of friction associated with the clamping force which reduces the relative sliding of the composite laminates. A significant lateral shift in the load-displacement curve as bolt torque increases can be seen in Figure 12. All the single lap joints underwent bearing failure with significant bending of the laminates.

\section{Load Displacement}

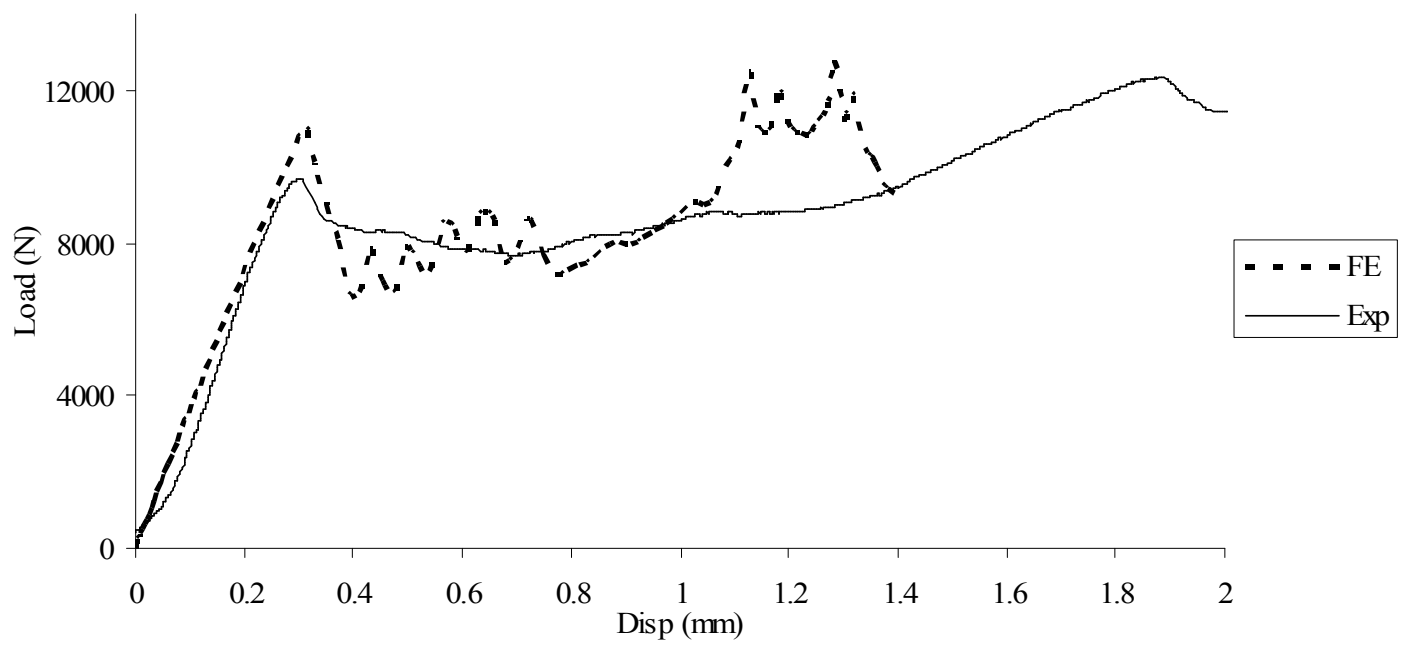

Figure 10. Load-displacement curve.

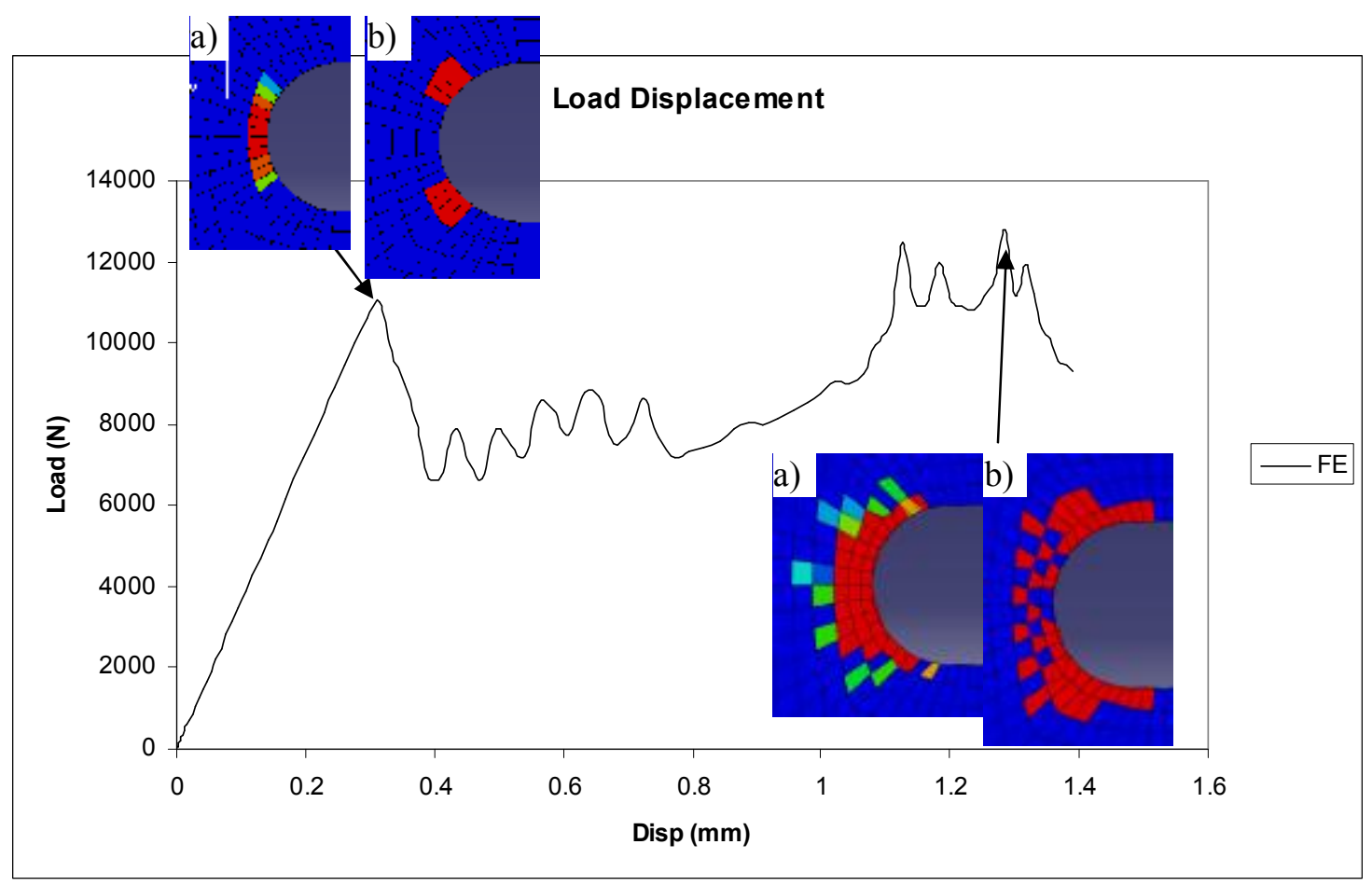

Figure 11. FE load-displacement with failure progression in $0^{\circ} \mathrm{ply}$.

The Figure 13 shows the comparison between experimental and simulation result for single lap joint with zero torque. The predicted ultimate failure load is within $1.5 \%$ of the experimentally achieved value. The initial stiffness is also well predicted. However the model over-estimates some results. The bearing failure is captured very well, as shown in Figure 14. The Figure 15 shows the extent of failure 
in the countersunk laminate and the non-countersunk laminate for joints with torque of BT1 listed in Table 2 .

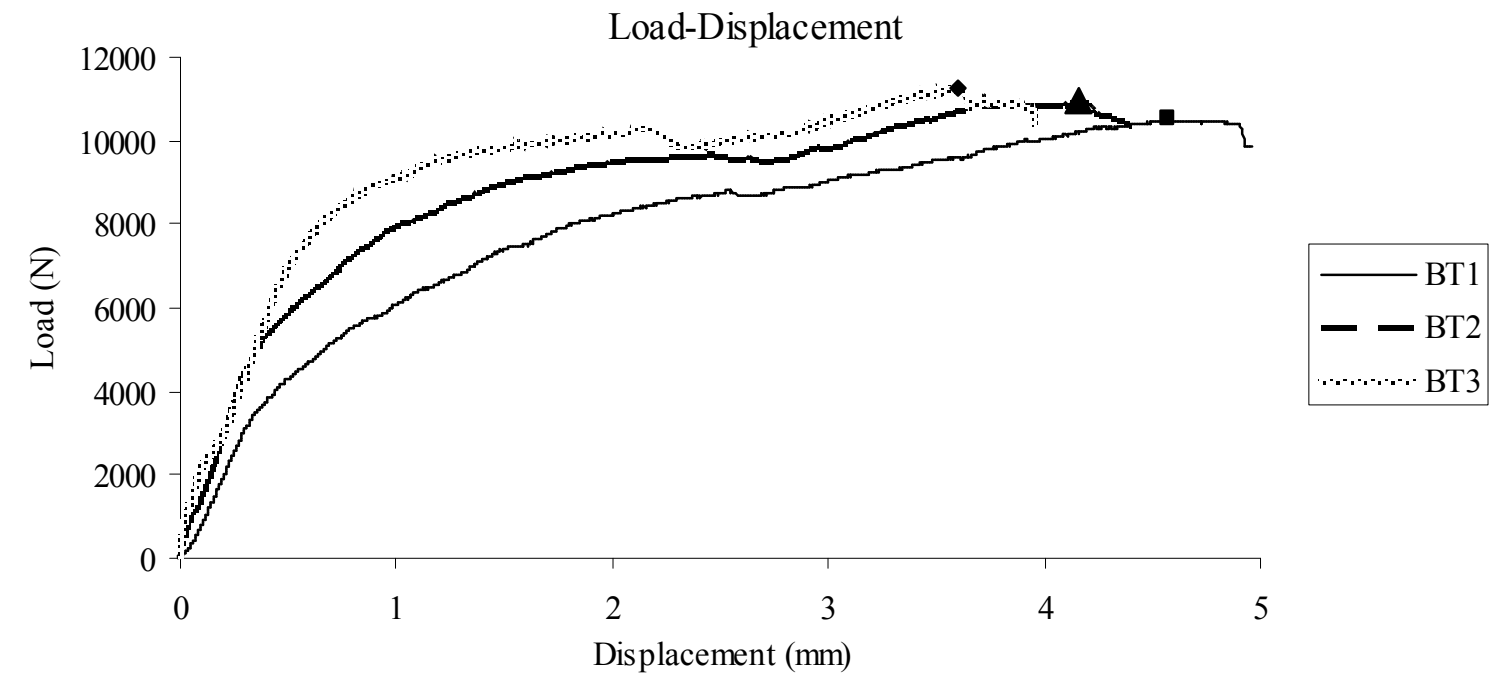

Figure 12. Experimental load-displacement curve for various bolt torques.

\section{Load-Displacement}

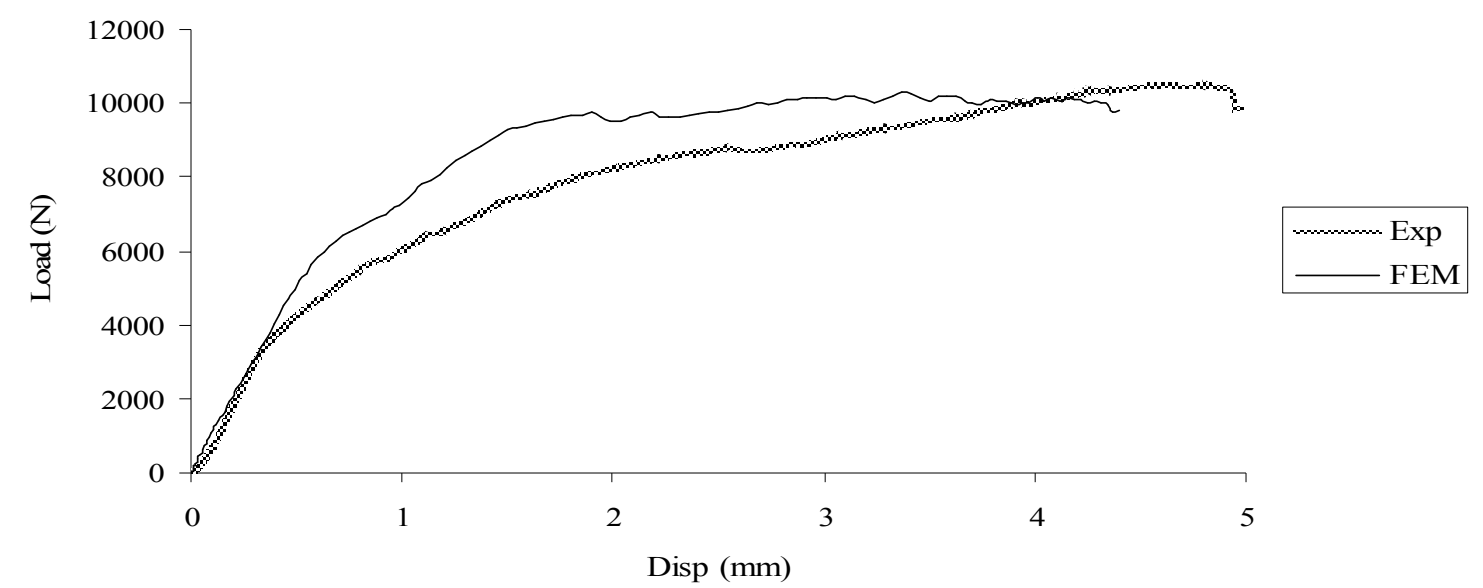

Figure 14. Load-displacement curve for torque BT1.

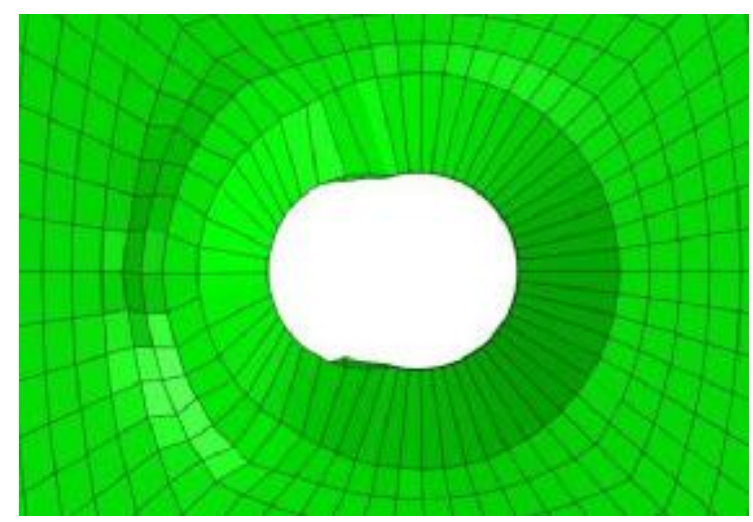

Finite Element

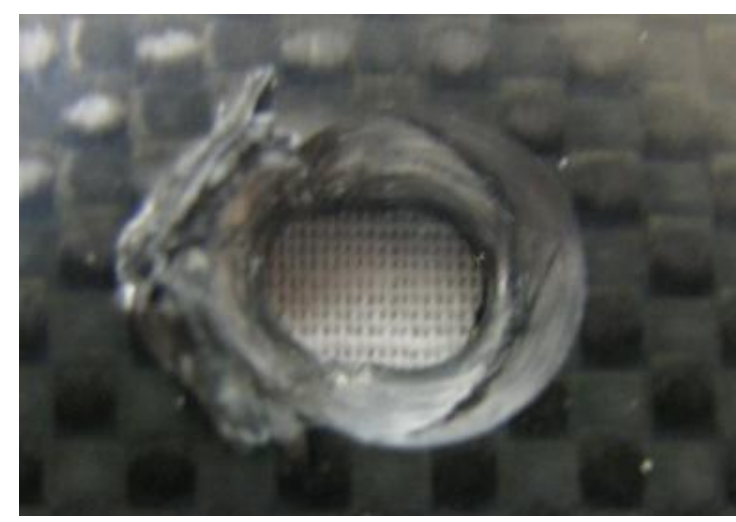

Experimental

Figure 13. Comparison of bearing failure for countersunk bolt 


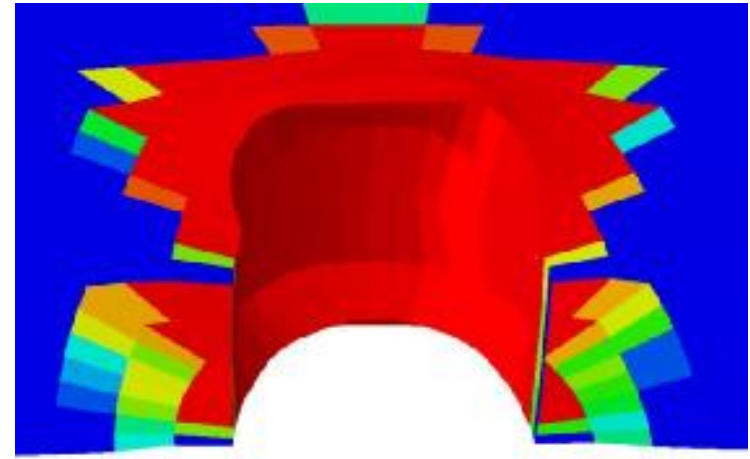

Laminate with straight hole

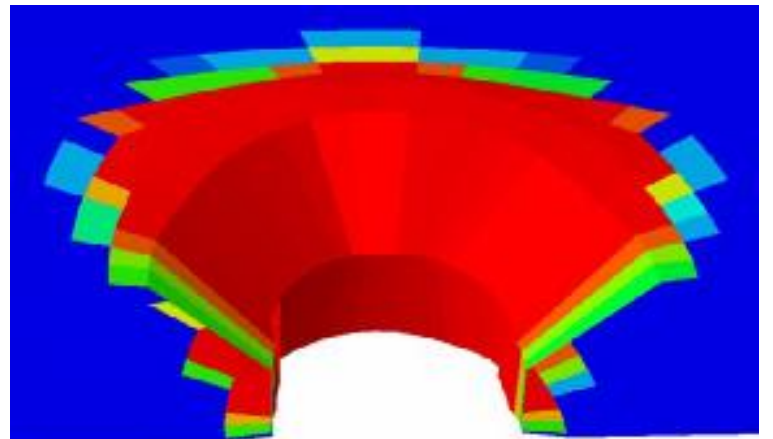

Laminate containing countersink

Figure 15. Fiber compressive failure in composite joint

\section{Conclusion}

Experimental and computational investigations have shown that bolt torque has a minimum effect on the strength of single-lap joints fastened using countersunk bolts. The computational model, in which composite ply damage is modelled using the crack-band based continuum damage mechanics approach, has been found to accurately predict the damage progression, initial stiffness and ultimate failure loads.

\section{Acknowledgements}

The authors acknowledge the financial support provided by Australian postgraduate award. The technical support of Mr. Peter Taktchyk (RMIT University) and Mr. Daniel Bitton (CRC-ACS) is also greatly acknowledged.

\section{References}

[1] Tsepres K I, Papanikos P and Kermandis Th 2002 A three dimensional progressive damage model for bolted joints in composite laminates subjected to tensile loading Fatigue Fract Engng Mater Struct 24 673-86

[2] Koerber, H. and P.P. Camanho. Simulation of progressive damage in bolted composites joints. in 13th European Conference on Composite Materials. 2008.

[3] Ireman T 1998 Three-dimensional stress analysis of bolted single-lap composite joints Comp struct 43 195-216

[4] Bhargava A and Shivakumar K N 2007 A three-dimensional strain concentration equation for countersunk holes J. Strain Analysis 43 75-85

[5] ASTM D5961, "Standard test method for bearing response of polymer matrix composite laminates"

[6] Hi-Lok ${ }^{\circledR}$ fastener standard

[7] ABAQUS 6.9 user manual

[8] Hashin Z Rotem A 1973 A fatigue failure criterion for fiber-reinforced materials $J$ compos mater 7 448-64

[9] Echaabi J, Trochu F and Gauvin R 1996 Review of failure criteria of fibrous composite materials Polymer Comp 17 786-98

[10] Paris F 2001 A study of failure criteria of fibrous composite materials NASA CR-210661

[11] Xiao Y, Wang W, Takao Y and Ishikawa T 2000 The effective friction coefficient of a laminate composite, and Analysis of pin-loaded plates J Comp Mater 34 69-87

[12] Xiao Y and Ishikawa T An experimental investigation of the bearing failure mechanisms in bolted composite joints $13^{\text {th }}$ Int. Conf. on Composite Materials June 25-29 2001 Beijing 